\title{
Current problems of protecting the rights and freedoms of socially unprotected citizens in the new economic realities
}

\author{
Ilmira Shikula ${ }^{1,2, *}$, Natalya Mishina ${ }^{1}$, and Yulia Gavrilova ${ }^{2}$ \\ ${ }^{1}$ Moscow International University, Leningradsky Av., 17, 125040 Moscow, Russia \\ ${ }^{2}$ Moscow City University, 2nd Agricultural passage, 4, building 1, 129226 Moscow, Russia
}

\begin{abstract}
: in the article, the authors consider the main directions of economic and social protection of persons with disabilities (disabled people, children), analyze the problems of socio-economic rehabilitation of low-mobility groups of the population, children, and suggest the main directions for optimizing economic policy in the field of support for particularly vulnerable citizens in difficult economic realities. Based on General theoretical methods of analysis and synthesis, generalization, citation, and axiomatic method, the authors conclude that if until now law enforcement practice has focused only on the principle of the best interests of the child, then in the new economic realities, the principle and the right of children to participate in decision-making on all issues that affect them should be of crucial importance. In this regard, the authors believe that in the sphere of social and economic protection of the rights of socially vulnerable citizens at the present stage, it is necessary to increase the effectiveness of law enforcement agencies in the field of prevention and suppression of violations of economic and social rights of the studied category of citizens, including the right to education, rehabilitation, economic support, which requires improvement of legal mechanisms that provide for a system of measures for the implementation of medical, vocational rehabilitation, secondary and higher professional education.
\end{abstract}

\section{Introduction}

The economic stability of the state and the efficiency of citizens ' life is the implementation of an optimal economic policy to protect the economic and social rights of citizens, including the most vulnerable in the economic and social aspect of citizens - all this is one of the most important priorities of the national policy of the Russian state

Russian Federation - this state of law, economic and social policy which aims to create the optimal economic mechanisms to create the necessary conditions for a dignified social life of every citizen in modern economic realities, with one of the mandatory indicators that distinguish a welfare state from the other, is considered to be the constitutional strengthening of the main social rights of man and citizen, the economic and social policies

\footnotetext{
* Corresponding author: ila.vnii@mail.ru
} 
aimed at their promotion and protection, including the right to judicial protection of economic and social rights in the Russian Federation.

\section{Methodology}

The authors of this research work used the following General theoretical methods as a methodological basis. The method of analysis as the main method of scientific understanding and cognition, which assumes the ascent to the beginning, provides and implements a mental analysis of a single ontologically whole for the sum of ontologically particular units. This method is used in applied analytical research, which is the present work. Synthesis method, as a procedure aimed at combining individual elements or components to form a single whole. It is the scientific synthesis of multiple parts that allows us to obtain a previously non-existent theoretical entity that has a synergistic effect, the emergence property, reflecting the presence of integrity properties in the synthesized system. Scientific synthesis is the basis of legal understanding and legal interpretation of the problem studied by the authors. The authors use the axiomatic method as one of the methods of deductive construction of theories. An axiomatically constructed theory is based on axioms, i.e. propositions are accepted without proof, and all other propositions of the theory are deduced based on logical conclusions. The paper also uses the citation method as a method of argumentation, illustration, and reference load. The authors use the comparison method to compare the features, features, and characteristics of the objects under study in order to find similarities and differences between them and to describe them. The method of generalization in its particular manifestation as a method of systematization is also used by the authors in this study.

\section{Research result}

The protection of the most vulnerable members of society is an important indicator of the effectiveness of the state's law enforcement function. Taking into account the fact that Russia is a social state, one of the main tasks of which is to create conditions that ensure a decent human life (part 1 of article 7 of the Constitution of the Russian Federation), the economic protection of socially vulnerable citizens is becoming more relevant in the new economic realities.

The exclusively social orientation of the constitutional reform in 2020 confirmed the existence of a demand in society for the highest standards of protection of human rights and freedoms, a harmonious existence of the individual, and safe living conditions (on July 1, 2020 , as a result of the all-Russian vote, the new version of the constitutional provisions gained legitimacy, and it was social initiatives that were most in demand among Russians). However, many topical issues related to this area have not yet been adequately addressed. In addition to the lack of social facilities for the most vulnerable categories of Russian citizens, there are a number of aspects that do not ensure an adequate level of their protection by the state.

One of the priority tasks of the Russian state in accordance with article 7 of the Constitution of the Russian Federation is to protect the rights of the most socially vulnerable citizens - persons with disabilities. It is the economic and social protection of persons with disabilities that is based on constitutional and legal postulates about human rights and freedoms [3, p. 46-47].

The Convention on the rights of persons with disabilities - a UN Convention adopted by the General Assembly on December 13, 2006 and entered into force on may 3, 2008 in article 7 States: 
"1. States parties shall take all necessary measures to ensure the full enjoyment by children with disabilities of all human rights and fundamental freedoms on an equal basis with other children.

2. in all actions concerning children with disabilities, the best interests of the child shall be given priority.

3. States parties shall ensure that children with disabilities have the right to freely Express their views on all matters affecting them, which receive due weight appropriate to their age and maturity, on an equal basis with other children, and to receive assistance appropriate to their disability and age in the realization of this right."

At the same time, the Convention adopted and entered into force its optional Protocol, which was signed by 90 States out of 155 signatory countries. 76 and 126 States have ratified, respectively. With the entry into force of the Convention, the Committee on the rights of persons with disabilities was established, a Supervisory body responsible for reviewing reports of States parties to the Convention, making suggestions and General recommendations on them, and considering reports of violations of the Convention by States parties to the Protocol.

Article 7 of the CRPD should be considered the most important article in relation to the rights of children with disabilities in the human rights system, and its significance should be well understood.

Disabled person - a person who has health disorders with persistent disorders of body functions caused by diseases, consequences of injuries or defects, leading to restriction of life and causing the need for social protection [1, p.146].

Federal law No. 181-FZ of 24.11.1995" on social protection of disabled people in the Russian Federation " (hereinafter - Federal law No. 181-FZ) defines a number of legal guarantees that determine the state policy in the field of social protection of disabled people in Russia: economic and social conditions that contribute to the adaptation of disabled people in society, improving their standard of living.

However, in modern Russian society, the problem of disabled people and their adaptation in society remains relevant.

In our opinion, personal disability itself should not be considered as a problem of a particular person, but as a problem of society as a whole, the problem of its social viability and moral choice.

It should also be taken into account that in the context of digitalization and the transition to an innovative model of economic development, not only the conditions for obtaining high-quality education and professional employment, but also the very daily life of a person, are significantly changing. And the legal mechanisms that have recently been relatively successful in solving the problem of protecting the rights of people with disabilities no longer correspond to the new pace of development, the new socio-economic situation [2, p.45].

Despite the fact that Russia currently has many different programs for economic support, social adaptation and rehabilitation of disabled people (providing legal, medical, social support, etc.), the analysis of law enforcement practice shows the opposite.

For example, persons with disabilities who have the right to legally receive medicines do not have the opportunity to freely and fully exercise this right.

Article 13 of Federal law No. 181-FZ "About social protection of invalids in the Russian Federation" is specified as a requirement for free or on preferential terms the provision of quality health care, including drug coverage, in accordance with the legislation of the Russian Federation and laws of subjects of the Russian Federation, however, there are cases of violations of the rights of persons with disabilities for preferential provision of medicines, as well as violations of legislation regulating additional medicines such persons. 
In accordance with the provisions of the state program of the Russian Federation "Accessible environment" for 2011-2020", aimed at improving the quality of life of disabled people and low-mobility groups of the Russian Federation, subsidies are provided to the budgets of the subjects of the Russian Federation, local budgets to co-Finance their expenses, within the framework of state (municipal) programs to ensure the availability of priority facilities and services in priority areas of life of disabled people.

The Prosecutor's office has repeatedly identified violations in the implementation of activities to provide medicines to patients who are entitled to receive them free of charge, while the reasons for the lack of medicines are often not the conclusion of contracts for their purchase and failure to implement programs of state guarantees of free medical care.

In addition, a common violation of the rights of persons with disabilities is the failure of Federal institutions of medical and social expertise to develop an individual rehabilitation program for a disabled person.

Currently, there is also an inefficiency of legal regulation that ensures the implementation of the labor rights of disabled people: the inability of workplaces, the lack of necessary equipment and tools specifically for disabled people, and the regulations in this area are exclusively departmental and in many cases non-systemic in nature [4, p.55].

A serious disadvantage in the rehabilitation of disabled people is the underdeveloped legal framework at the regional level, the lack of adequate funding for rehabilitation of disabled people in a particular region $[5$, p. 76$]$.

In addition, you must pay attention to the problems of social protection of children from domestic violence to economic realities, this phenomenon is recognized also on a practical level, and uses a variety of social institutions (in particular, accumulates information about the social- the economic situation of the family in a situation of domestic violence, create crisis centers, aktiviziruyutsya preventive work), but not fully developed legal mechanisms (there is no legislation on prevention of domestic violence), law enforcement is no victimological account of the victims of domestic violence, not in full use the whole Arsenal of victimological prevention of domestic violence, etc., therefore, ensuring the social and economic protection of children from domestic violence should be one of the priorities of state policy in the field of child protection in General.

I always want to think and believe that in our family, as in a safe haven, we will be able to hide from the stress and overload of our troubled world, no matter what threatens us outside the home, we hope to find protection and support in the love of those with whom we maintain the closest relationship. However, for many people, the desire for family peace turns out to be impossible, since their loved ones are a source of threat rather than reliability and security. Taking out aggression and anger on others, especially on the weaker oneswomen, children, the elderly and the disabled-knows no political or geographical boundaries. About 200,000 family brawlers are registered with the police, but the true scale of family violence is not limited to these figures. The fact that society itself is not ready to openly discuss this problem, as well as the victims themselves, contributes to the growth of such violence to a greater extent [7, p.27]. Domestic violence against children is a rather acute, complex and urgent social problem.

This type of crime among all violent crimes is estimated by experts to be almost $50 \%$. Moreover, it is necessary to keep in mind the significant level of latency of family violent crimes, due to the fact that the family is a relatively closed social institution. Social phenomena such as social tension, the low standard of living of the majority of the population in our country, the sharp differentiation of society on the basis of property, people's uncertainty about the future, including the political situation in the country, also play an important role here.

Only according to official law enforcement data, every third murder is committed in the family. More than 50 thousand children run away from home every year, fleeing from the 
"hot love" of their relatives or guardians. Every year 7 thousand children become victims of sexual crimes [1, p. 250]

Domestic violence against children is a rather acute, complex and urgent social problem. The General crisis of Russian society significantly exacerbates social problems, which primarily affects the most vulnerable categories of society.

Family law generally protects minor children from violence and ill-treatment by their parents or their surrogates. Thus, article 77 of the Family code of the Russian Federation establishes the procedure for taking a child away from his parents or other persons who have him, if there is an immediate threat to his life or health.

In virtue of their nature, home crimes have a high degree of latency, the main part of victims of such crimes do not seek help from law enforcement for fear of retaliation by the perpetrator, lack of trust in the solvability of conflicts with law enforcement.

The main types of domestic violence against children are: physical violence, sexual violence, neglect of the child's needs, emotional (psychological) violence, and economic violence.

The social consequences of domestic violence against children are very significant and diverse, they can be:

- $\quad$ nightmares, sleep disorders, fears of the dark, people, fear of anger;

- attempts to commit suicide, loss of life washed away, goals in life (in adolescents);

- delay in physical and speech development, growth retardation (in preschool and primary school children);

- violation of mental States: depression, sadness, helplessness, hopelessness, lethargy, feeling of helplessness;

- negative consequences for personal development: violations of the Selfconcept: perception of oneself as bad (stigmatization), guilt, depression;

- formation of the model "love is always associated with sacrifice, pain", violation of the ability to build long-term partnerships;

- formation of negative character traits: impulsivity, explosiveness, bad habits (nail biting, hair pulling), malice; excessive compliance, compliance; unpredictability (even for oneself), constant ambivalence of experiences: the presence of both love and hatred for the person who subjected the child to violence, etc. [4, p. 53].

The relationship of a child who is subjected to domestic violence with other people is as follows: he does not trust the people around him; faces difficulties in establishing contacts with other people; tends to show aggression towards other people; refuses to interact; tends to self-isolate. As an adult, a child who has previously been subjected to domestic violence later shows aggression towards their loved ones. [4, p. 54]

We consider domestic violence against children as systematically repeated acts of physical, economic, psychological, and sexual influence on a child by family members, which are committed against their will in order to gain power and control over them.

Economic-social rehabilitation of children from domestic violence is viewed as a set of economic, social, socio-medical, psycho-pedagogical, socio-legal measures applied by the specialized bodies aimed at reducing aggression and anxiety in the child, adapting them to the society, etc.

Coordination between bodies and institutions of system of prevention of neglect and offenses makes it more efficient to identify cases of domestic violence, measures of sociallegal protection of children and other family members, the organization of the psychosocial rehabilitation work with victims of violence (child helpline, non-governmental organizations; the Commission on Affairs of minors and protection of their rights; coordinating Council on the implementation of the policy in the interests of families and 
children; the interdepartmental Commission on the organization of rest, improvement and employment of children, adolescents and youth, etc.).

The current paradigm of children's rights was embodied in the 1989 United Nations Convention on the rights of the child (CRC). Since this was a new paradigm, its roots and consequences were very different and numerous. However, it can still be argued that the fundamental change this led to was to stop treating the child as a legal "object" of protection and instead start treating it as a legal "subject". In other words, this has led to the child being no longer perceived as a person of recognized value, who therefore deserves the protection that the law should guarantee, but who is nevertheless characterized as a defenseless, imperfect and incapable person and is therefore deprived of the right to exercise his or her rights throughout his or her childhood. Rather, it was considered that although the child continues to be characterized by their special helplessness and inability in important respects, thus justifying the emphasis still should be on the special protection he needs to ensure he is also the person who should be able to accept as possible that decisions for the direction of his life. In other words, given the evolution of a child's abilities at various stages of life, their opinion should be taken into account in all decisions affecting the child, even if it still needs to be evaluated by qualified third parties in accordance with their age and maturity.

So, based on this new paradigm of "renewed" protectionism, it is necessary to consider two main ideas concerning the recognition and protection of children's rights: first, that some basic aspects of a child's life should be protected by law. These aspects, which are considered necessary for the child's proper development as a person, can be considered as constituting, according to article 3.1 of the CRC, the "best interests of the child", which is a principle that has been supported by "traditional" protectionism. Second, that the child should participate, in accordance with their age and level of maturity, in the decisionmaking process that is carried out in relation to issues that affect the child, in accordance with article 12 of the CRC, which is a new principle that will lead to changes encouraged by "renewed" protectionism. Consequently, two fundamental pillars are established on which the theoretical construction and legitimation of the modern model of recognition and protection of children's rights is based. As already noted, this model was approved by the CRC and subsequently reflected in the last two paragraphs of article 7 of the CRPD: protecting the best interests of the child and ensuring their participation in the decisionmaking process that inevitably affects the child. Based on this, Jorge Cardona considers these two principles/rights as "revolutionary" in relation to the previous situation and as "the Central axis of the paradigm shift" [9, p.23]. The relationship between these principles is obvious, which makes it possible to fully include the rights of children with or without disabilities in the human rights model [10]. That is, art. 7 the CRPD should be understood as the result of applying the principles underlying the current paradigm of children's rights to children with disabilities, in accordance with the changes required by the social model of disability.

\section{Conclusions}

Thus, article 7 of the CRPD implies applying the principles that support the current paradigm of children's rights promoted by the CRPD to children with disabilities, as required by the social model of disability. While up to now law enforcement has focused only on the principle of the best interests of the child, in the new economic reality, the principle and right of children to participate in decision-making on all issues that affect them should be given crucial importance.

In this regard, we believe that in the sphere of social and economic protection of the rights of socially vulnerable citizens at the present stage, it is necessary to increase the 
effectiveness of law enforcement agencies in preventing and suppressing violations of economic and social rights of this category of citizens, including the right to education, rehabilitation, and economic support, which requires improving legal mechanisms that provide for a system of measures for the implementation of medical, vocational rehabilitation, and secondary and higher professional education.

\section{References}

1. I. A. Alekseeva. Child abuse. Causes. Effects. Help, 256 (2013)

2. S.N. Belyasov, State and law: theory and practice: materials of the International scientific conference, 76, (2011)

3. T. Nikolaevna Korchagina, Bulletin of the Moscow City Pedagogical University, Series: Legal Sciences, 3 (39), 42, (2020)

4. V.A. Mishchenko, A.D. Ustyantseva. Bulletin of the Ugra State University, 1 (36), 53 (2015)

5. O.V. Efimova, A.V. Zvonareva, Large family: rights and guarantees under the legislation of the Russian Federation and the city of Moscow, 214 (2017)

6. I.R. Shikula, Criminal law protection of the rights and freedom of the victim, who is in a helpless state, from violent crimes: problems of theory and practice, 240 (2020)

7. I.R. Shikula, Actual problems of criminal and criminal procedure law: current state and development prospects: Sat. scientific works of the Department of Criminal Law Disciplines of the Institute of Law and Management of the Moscow State Pedagogical University, 83, 27 (2020)

8. O.Yu. Shchepetnova, Young scientist, 4 (242), 146 (2019)

9. J. Cardona Llorens, Revista española de desarrollo y cooperación (2014)

10. I. Campo Cervera, Derechos y Libertades, 37, 131 (2017) 